\title{
Desafios no Processo de Inclusão Digital no Ensino de Matemática em Escolas Públicas: Um Relato de Experiência do Projeto InfoMat
}

\author{
Cibelle Assis ${ }^{1}$, Ayla Dantas ${ }^{1}$, Flávia Souza ${ }^{1}$, \\ José Fabrício Lima de Souza ${ }^{1}$, Renata Figueiredo ${ }^{1}$ \\ ${ }^{1}$ Universidade Federal da Paraíba (UFPB) - Campus IV \\ Rua da Mangueira, sn, Companhia de Tecidos Rio Tinto, Rio Tinto - PB - Brasil \\ $\{c i b e l l e, a y l a, f l a v i a$, fabricio, renata\} edcx.ufpb.br
}

\begin{abstract}
Technology is changing the educational process and the school needs to adapt to this new scenario by offering to students resources of the digital world to ease their learning and to motivate them to study in a different way from the traditional method of teaching. In this paper, we describe an experience report about the planning and execution of an extension project in which we have put into practice the use of technology in mathematics education in public schools of City X. In this process we had to face a number of challenges. We believe that the experience reported here will be useful to encourage other cases of success in overcoming challenges in other cities of our country.
\end{abstract}

Resumo. Sabe-se que a tecnologia vem modificando o panorama da educação $e$ a escola precisa se adaptar a este cenário, oferecendo a seus alunos recursos do mundo digital que facilitem o seu aprendizado e os motivem a estudar de uma maneira diferente do método tradicional de ensino. Neste artigo será descrito um relato de experiência a respeito do planejamento e execução de um projeto de extensão em que se buscou efetivar o uso de tecnologias na educação matemática nas escolas da rede pública do município de Rio Tinto-PB e onde se teve de enfrentar uma série de desafios. Acredita-se que a experiência aqui relatada será útil para incentivar outros casos de sucesso na superação de desafios em outros municípios de nosso país.

\section{Introdução}

O uso das Tecnologias da Informação e Comunicação (TICs) no ensino de matemática tem sido cada vez mais incentivado. Sabe-se que se for feito um uso adequado de tais recursos se consegue promover a descoberta, a motivação para o estudo e o desenvolvimento do pensamento matemático dos alunos. Observa-se que as crianças e jovens da atualidade são nativos digitais e que a escola precisa se adaptar a este novo cenário e oferecer recursos digitais que facilitem o seu aprendizado e os motivem a estudar de uma maneira diferente das práticas escolares atuais. No entanto, há uma série de desafios a enfrentar nesse processo, principalmente em escolas públicas de nosso país. No município de Rio Tinto-PB, por exemplo, ainda são raras as experiências de uso de recursos de TICs no ensino de matemática. Além disso, neste mesmo município, 
são muito baixos os índices de avaliação de aprendizagem como o IDEB e o índice de rendimento da Prova Brasil em Matemática.

Considerando esses aspectos, foi iniciado um projeto de extensão denominado InfoMat e que teve como objetivo realizar ações para fortalecer o exercício da prática docente em matemática nas escolas públicas do município, integrando a comunidade escolar com alunos e professores da universidade envolvidos nos cursos de Licenciatura em Ciência da Computação, Sistemas de Informação e Licenciatura em Matemática. O foco era a promoção da inclusão digital dos alunos e professores das escolas por meio do ensino de matemática apoiado por recursos de TIC. A troca de experiências entre todos os envolvidos no projeto foi muito proveitosa e marcada pela superação de diferentes desafios, que serão discutidos neste trabalho junto com algumas lições aprendidas, apresentadas à luz da literatura na área. O objetivo deste trabalho é mostrar formas de superar desafios que ainda perdurarão por pelo menos dez anos, como a necessidade de apoiar os professores na inclusão da informática na educação em termos pedagógicos e técnicos, a necessidade de saber selecionar bem softwares educacionais a utilizar, a necessidade de construir novos softwares que atraiam os nativos digitais que temos hoje em dia e que dificilmente irão querer fazer da forma tradicional no papel suas atividades, dentre outros.

Este trabalho está organizado da seguinte forma. A Seção 2 discute sobre tecnologias na educação e especificamente no ensino de Matemática. A Seção 3 descreve um dos desafios na inclusão digital no ensino de matemática e que é o planejamento de aulas de matemática envolvendo TIC junto aos professores das escolas públicas. A Seção 4 discute sobre o processo de seleção e avaliação de recursos digitais para apoiar no ensino de matemática. A Seção 5 aborda a necessidade de conhecer bem a realidade do ambiente escolar em termos de TIC por meio de diagnósticos antes de efetivamente atuar neste ambiente, dando sugestões de informações a coletar. A Seção 6 relata os desafios e resultados obtidos no projeto no processo de criação de objetos de aprendizagem para apoiar no ensino de matemática. Por fim, a Seção 7 apresenta as considerações finais deste trabalho e sugestões de trabalhos futuros.

\section{Tecnologias na Educação e no Ensino de Matemática}

De acordo com Healy, Janh e Frant (2010), a introdução dos computadores no cenário educacional brasileiro se deu nos anos 80. Porém, apesar de mais de 40 anos de história da informática na educação brasileira, e desta área de estudo ser considerada por Valente (1997) como uma área de pesquisa com identidade própria, raízes sólidas e relativa maturidade, a disseminação e utilização dos computadores nas escolas está muito aquém do que se anunciava e se desejava. $O$ acesso ainda limitado das tecnologias, em especial de computadores e Internet nas escolas públicas, foi e ainda é, certamente um grande problema. No entanto, segundo dados do Censo Escolar Brasileiro de 2012, divulgado pelo INEP (2013), o laboratório de informática é o recurso mais disponível nas escolas públicas, oferecido em $49 \%$ das escolas do ensino fundamental e presente em $92,4 \%$ das escolas de ensino médio. No entanto, em alguns casos não são usados, ou são subutilizados, e acabam ficando sucateados.

Para que o uso das tecnologias na educação seja efetivo e eficiente, é importante que o professor esteja preparado ou receba apoio para selecionar os recursos a utilizar e 
também apto para identificar as limitações de cada um. É neste apoio ao professor sob diferentes aspectos que o Projeto InfoMat se insere, pois há aí vários desafios.

Algumas iniciativas no sentido do uso da tecnologia no ensino-aprendizagem de matemática podem ser encontradas em vários trabalhos, como os de Peres, Lorenzi e Franco (2014) e de Toda et al. (2014). Peres, Lorenzi e Franco (2014) apresentam o jogo Castelo da Matemágica e Toda et al. (2014) apresentam um sistema web para auxiliar no estudo e treinamento para as Olimpíadas Brasileiras de Matemática. Um outro trabalho também relacionado é o de Castro Filho (2007). Segundo o autor, embora existam vários instrumentos, como Objetos de Aprendizagem (OAs), para apoiar o ensino de matemática, devem ser considerados diversos aspectos para que se tenha sucesso nesse processo, como o planejamento da aula e o acompanhamento do professor, que deve ter explorado antes os OAs utilizados. Nesse sentido, o presente trabalho apresenta algumas dessas estratégias sendo aplicadas na prática. Além disso, são apresentados os desafios encontrados nesse processo e as formas encontradas para superar tais desafios, observadas com a experiência de realização do projeto InfoMat.

\section{Planejando aulas que utilizam recursos de TIC}

Um dos primeiros desafios ao promover a inclusão digital no ensino de matemática é o planejamento das aulas, uma vez que vários professores não têm um forte domínio dos recursos de Tecnologia da Informação e Comunicação (TIC) que podem explorar e, por isso, às vezes demonstram um certo grau de resistência em tentar utilizá-los em suas aulas. Nesse sentido, se buscou durante a execução do projeto InfoMat ajudar os professores no planejamento e na execução de sequências didáticas para aulas de Matemática integrando recursos digitais (jogos e outros softwares educativos) ao desenvolvimento curricular. Durante este processo, os professores foram acompanhados por alunos e professores de Licenciatura em Matemática e Licenciatura da Computação, gerando uma troca de experiências muito importante e dando-lhes a segurança para trabalhar com algo novo e de forma contextualizada ao conteúdo que se queria abordar.

Para Valente (1997), a Informática na Educação ainda não se consolidou no nosso sistema educacional. Isso ocorreu principalmente porque as ideias dos educadores que a incentivaram não foram bem absorvidas ou talvez não foram compreendidas. $\mathrm{O}$ autor coloca que foram subestimadas as implicações das mudanças pedagógicas propostas no sistema educacional como um todo. Para essas mudanças são consideradas três dimensões: mudança estrutural das escolas, mudança da atuação dos professores e dos alunos no processo de ensino e aprendizagem, e consequentemente mudança na relação do aluno com o conhecimento. É exatamente sobre elas que se percebe os principais desafios do trabalho com a Informática na Educação.

$\mathrm{Na}$ segunda dimensão, sobre o envolvimento do professor nesse processo, segundo Miskulin (2009), "o ambiente, por mais rico e construtivo que seja, por si só, não é suficiente para promover contextos propícios à exploração e construção do conhecimento, no contexto tecnológico". Assim sendo, a mediação do professor desempenha um papel importantíssimo e determinante. O professor deve partir de uma concepção construtiva de aprendizagem para fundamentar a proposta de trabalho com softwares educativos. Dessa forma, a utilização dos softwares em sala de aula deve ser norteada por interesses pedagógicos e não apenas como um mero recurso ou para propor uma aula diferente, ou ainda por que os alunos gostam de computadores. 
Nesse sentido, durante o projeto InfoMat, se buscou discutir junto aos professores os interesses pedagógicos de algumas de suas aulas e sugerir softwares com os quais se pudesse atender a esses interesses, tendo o cuidado de se planejar aulas onde o aluno seria um sujeito ativo, como sugerido por Zimmerman (1998) e não apenas receberia o conhecimento já processado simplesmente, sem poder bem absorvê-lo. Além disso, se deveria planejar bem, pois segundo Fernandes et al. (2009), informatizar os métodos tradicionais de instrução não é suficiente para provocar mudanças.

O planejamento das aulas com os professores envolvidos no projeto InfoMat teve início a partir da definição dos horários das aulas por turma e série, a perspectiva dos conteúdos a serem trabalhados nos próximos meses e a forma de intervenção dos alunos da universidade (apoio pedagógico como atividade extraclasse ou com intervenção didática na sala de aula).

A maioria dos professores das escolas optou pela intervenção em sala dando continuidade ao conteúdo que estivesse sendo trabalhado no momento. Esses dados foram organizados e compartilhados em uma planilha no formato Google docs, como forma de facilitar a comunicação e compartilhamento de informações entre os membros da equipe já que qualquer um poderia editar a planilha e visualizá-la online. Esta planilha continha as informações sobre a distribuição dos alunos bolsistas entre as aulas planejadas, os professores das escolas que atenderiam, turmas e conteúdos que seriam trabalhados, além da previsão das datas e horários das aulas. Uma das abas da planilha era alimentada por alunos bolsistas do curso de Licenciatura em Computação sob a orientação dos professores do curso e continha informações sobre objetos de aprendizagem (OAs) digitais que iam sendo encontrados e relacionados aos conteúdos que seriam trabalhados nas aulas que estavam sendo planejadas pelos alunos do curso de Licenciatura em Matemática (LM) junto com os professores das escolas, também sob a supervisão de professores do curso de Matemática. Para cada OA selecionado havia informações como URL para que pudesse ser baixado ou acessado, descrição, conteúdo, indicação de série, forma de execução, além de uma imagem representando uma das telas do OA. Considerando essa seleção, os alunos de licenciatura em matemática apoiavam os professores das escolas na preparação das aulas de matemática. Além de informações sobre os OAs, também eram compartilhados pelo documento online avaliações de OAs e sugestões de planos de aulas, a partir de consultas sobre aulas disponíveis nos sites Portal do professor do Ministério da Educação - MEC (portaldoprofessor.mec.gov.br) e da Revista Nova Escola (revistaescola.abril.com.br) voltadas para conteúdos de Matemática do Ensino Fundamental e Médio que poderiam ser utilizados pelos alunos bolsistas do curso de Licenciatura em Matemática nas escolas.

Paralelamente a este trabalho, os alunos discutiam com seus orientadores sobre o planejamento e execução das aulas, um aspecto importante para sua formação de licenciados, analisando a adequação dos objetivos da aula com os objetos de aprendizagem encontrados, as condições estruturais da escola e questões metodológicas como o perfil da turma e complexidade dos objetos escolhidos, além de questões trazidas pelos professores das escolas.

$\mathrm{Na}$ hora de selecionar um OA para uma aula que estava sendo planejada, se buscava responder a questões como a sugerida por Van de Walle (2009): a atividade pode ser melhor realizada sem o computador? Este autor recomenda que não se use o 
software apenas para que seus alunos usem o computador e que se foque no que os estudantes estarão aprendendo ao usar o software. É importante verificar como os estudantes serão envolvidos com o conteúdo (não com os sinos e apitos de acerto ou erro) e lembrar-se de que o pensamento reflexivo do estudante é o fator mais significativo no ensino eficaz. Outro aspecto importante é observar se o programa é fácil de usar. Os estudantes devem sentir-se motivados e não entediados com o uso do programa. Caso contrário, terão a atenção desviada do conteúdo e ficarão frustrados. Se deve também verificar que tipo de informação conceitual é fornecida. O professor deve refletir sobre como as respostas erradas são abordadas e como os modelos ou explicações vão ajudar na compreensão dos estudantes. O professor ainda deverá ter em mente que o software deve contribuir com os objetivos da lição ou da unidade, que não deve ser usado como acréscimo ou substituição e que pode ser planejado o uso individualizado ou em pequenos grupos, separando um tempo para os estudantes explorarem livremente ou praticarem algum conteúdo usando o software. É importante também combinar atividades usando o software com atividades fora do computador e avaliar o software utilizado.

De maneira geral, acredita-se que a parceria entre alunos da área de informática e matemática no projeto InfoMat observando esses aspectos gerou uma experiência muito positiva. Um outro aspecto positivo observado na experiência do projeto InfoMat foi o uso do Google Docs para compartilhamento de informações e planejamento. O produto final do planejamento para cada aula feito em conjunto com os professores responsáveis pelas turmas era apresentado em forma de Plano de Aula, que tinha de ser aprovado por tais professores antes de aplicado.

\section{Selecionando e avaliando recursos digitais para apoiar no ensino de matemática}

Um outro desafio no processo de inclusão digital no ensino de matemática é a seleção e avaliação dos recursos digitais existentes para apoiar as aulas planejadas. Embora existam diversos recursos, é importante que estes sejam catalogados por conteúdo e avaliados utilizando critérios pedagógicos e técnicos, como proposto por Reategui e Finco (2010). Pode-se ainda utilizar critérios como usabilidade, além dos critérios pedagógicos, como proposto no Método de Revees [Campos 1989]. Para selecionar e avaliar objetos de aprendizagem (OA), uma parte da equipe do projeto ficou focada na seleção dos recursos mais interessantes e alinhados aos conteúdos programados pelos professores de matemática, alimentando a planilha do Google Docs utilizada para planejamento pelo projeto. Na busca se utilizou por base o Portal do Professor (http://portaldoprofessor.mec.gov.br/index.html), o RIVED (http://rived.mec.gov.br), e outros repositórios de materiais como o site do GeoGebra (http://www.geogebra.org/cms/) e sites independentes. Nesse processo, era importante que se pudessem selecionar OAs que não dependessem de Internet, já que em algumas escolas o link disponível é bem pequeno ou não há Internet. Os OAs selecionados e avaliados eram incorporados nas sequências didáticas sendo planejadas.

Segundo Miskulin (2009), a escolha do software a utilizar com os alunos relaciona-se com diversos aspectos teóricos e metodológicos. À medida que o professor utiliza a tecnologia para "criar situações desafiantes", ele faz o aluno "perceber problemas por outra perspectiva" possibilitando a "busca de novos caminhos", a 
"constante reavaliação de suas estratégias e objetivos, envolvendo-se no processo de construção do conhecimento".

Ao escolher um software, o professor deverá, segundo Miskulin (2009), considerar algumas de suas características computacionais e educacionais. O professor deverá identificar quais as possibilidades do software, por exemplo, se permite repetição e prática, se permite simulação, se serve para resolver problemas, se é apenas uma ferramenta para cálculos, se é de geometria dinâmica. Por isso, é muito importante que o professor estabeleça critérios para selecionar e utilizar um software educativo.

Segundo as Orientações Curriculares para o Ensino Médio (OCEM) [Brasil 2006] e Van de Walle (2009), os software apresentam recursos que provocam, de forma muito natural, o processo que caracteriza o pensar matematicamente, ou seja, os alunos fazem experimentos, testam hipóteses, esboçam conjecturas, criam estratégias para resolver problemas. Considerando isso, é importante observar todos esses aspectos ao se selecionar um objeto de aprendizagem matemático para trabalhar em sala de aula e com base nisso, alguns dos objetos selecionados para as aulas do Projeto InfoMat foram o objeto chamado Eixo Cartesiano ${ }^{1}$, o Objeto de Aprendizagem jogo Labirintos da Matemática $^{2}$, e também o software Geogebra. Sobre o envolvimento dos alunos nas aulas, pode-se afirmar que estes se mostraram participativos, curiosos e empolgados com as atividades envolvendo os OAs, contrariando colocações dos professores regentes antes da atividade sobre a participação dos alunos nas aulas de matemática e seu envolvimento em atividades.

\section{Conhecendo a realidade do ambiente escolar em termos de TIC e atuando neste ambiente}

Ao longo do projeto, um outro desafio encontrado foi observar que vários laboratórios de escolas públicas não passam por manutenção, têm poucas máquinas de fato funcionando e são pouco utilizados. O projeto permitiu que alguns laboratórios fossem reativados e trouxe uma ideia nova, que é a de levar o laboratório de informática à sala de aula, por meio de notebooks e tablets que eram levados já com os softwares necessários para as atividades planejadas. No caso do projeto, isso foi feito com computadores e dispositivos móveis (tablets) da universidade, mas se observou que seria interessante que a escola pudesse ter seus laboratórios neste estilo itinerante e que é importante que eles possam ser preparados para a aula, evitando que o aluno se disperse em outras atividades no computador.

Observou-se pela experiência que é importante conhecer a realidade da escola, pois às vezes com o recurso que ela já dispõe se pode fazer uma grande diferença. Além disso, é importante conhecer os alunos com relação à sua prática no uso de recursos de TIC. Nesse sentido, no início do projeto InfoMat, se buscou aplicar nas escolas que seriam atendidas alguns questionários com os professores, alunos e direção. Dessa forma, foi possível ter uma visão geral da realidade de cada escola, de seus professores e alunos quanto à utilização de recursos digitais para auxiliar no planejamento.

\footnotetext{
${ }^{1}$ http://www.rpedu.pintoricardo.com/Actividades_interactivas/coordenadas_2.php

${ }^{2}$ http://www .somatematica.com.br/softw/labirintos.zip
} 
Considerando alguns dos aspectos investigados no levantamento diagnóstico da realidade escolar, observou-se que dos 13 professores que participaram do levantamento, a grande maioria deles (12 professores) possui computador com Internet em casa. 10 professores acessam Internet todos os dias, 2 professores usam raramente e 1 professor usa Internet algumas vezes na semana. Entre os recursos utilizados, o editor de texto é usado por 9 professores, 2 professores utilizam planilhas, 9 professores utilizam redes sociais e 9 professores utilizam sites de busca. Apenas 4 dos 13 professores afirmaram que utilizam o laboratório de informática para as aulas de Matemática, sendo que só um professor utiliza quase todos os dias e dois utilizam poucas vezes na semana. Entre as principais razões citadas para o não uso do laboratório estão a falta de estrutura da escola e dois professores citaram que não se sentiam preparados. No entanto, 5 professores entre os 9 que não utilizam o laboratório disseram que gostariam de utilizar o laboratório. Percebeu-se que os professores pouco conheciam sobre os softwares educacionais instalados nos computadores das escolas. Apenas 3 citaram o Geogebra e 1 citou a planilha eletrônica como exemplos de softwares que poderiam explorar.

Quanto à realidade dos laboratórios das escolas, a escola A possui 19 computadores em seu laboratório de informática, sendo que apenas 10 estão funcionando e utilizando o sistema operacional Linux Educacional. Os softwares instalados no laboratório desta escola para o apoio de Matemática são os seguintes: Kalgebra, KmPlot, KBruch, Geogebra, Klg, Contar. Porém, apenas um professor do Ensino Médio do turno da tarde faz uso do laboratório com frequiência, principalmente, explorando o Geogebra. Os outros professores não fazem uso destes softwares. A Escola B possui 8 computadores em seu laboratório de informática, sendo que todos estão funcionando. Os principais softwares instalados no laboratórios são os softwares básicos padrões do Windows XP. Os professores de Matemática não exploram o laboratório junto com os alunos e não há nenhum software de apoio à Matemática instalado nos computadores desta escola. As duas escolas possuem internet de $2 \mathrm{MB}$.

Para se traçar o perfil dos alunos quanto ao uso da informática, Internet e dispositivos móveis em seu cotidiano, foram aplicados 475 questionários, o que corresponde a uma amostra de $30 \%$, em 24 turmas dessas escolas do $6^{\circ}$ ano do ensino fundamental ao $3^{\circ}$ ano do ensino médio, sendo a maioria do $8^{\circ}$ (25,7\% do total), do $6^{\circ}$ $(19,6 \%$ do total $)$ e do $9^{\circ}$ ano $(15,4 \%)$.

Dentre os alunos que responderam, $61 \%$ declarou que detém conhecimento ao menos básico de informática. Além disso, 40,21\% afirmaram possuir computador em casa. Considerando sua frequência de acesso à Internet, 35,16\% afirmaram acessar a Internet todos os dias e 40,63\% afirmaram acessá-la algumas vezes na semana. Outro aspecto observado foi que $67,79 \%$ informaram que utilizam os computadores para atividades cotidianas. Quando questionados sobre possíveis tipos de atividades, alguns dos usos mais comuns foram navegação em redes sociais $(41,05 \%)$ e sites de busca $(46,95 \%)$. Apenas $8,63 \%$ citaram e-mail como um dos usos e $12,42 \%$ citaram o uso de editores de texto.

Observar estes aspectos foi importante, pois ao introduzir o uso de um software educacional em uma aula ou ao utilizar durante a aula um dispositivo como notebook ou tablet, teria-se de considerar que parte da turma já tinha familiaridade com tais dispositivos e parte não. Uma estratégia interessante adotada durante o projeto InfoMat 
foi colocar os alunos em grupos no momento de desenvolver as atividades, o que estimulou o trabalho em equipe na resolução dos exercícios, mas também a troca de experiências entre os alunos quanto ao uso dos recursos de TIC.

Para Valente (1997), existem diferentes maneiras de usar o computador na educação. Na perspectiva de promover a interação dos alunos com objetos de estudo em um ambiente computacional, o aluno não é mais instruído, ensinado, mas é o construtor do seu próprio conhecimento. Nesse sentido, acredita-se que trabalhos em equipe utilizando recursos de TIC estimulam esse processo.

Além disso, é importante destacar que Cury (2007) sugere que se pense em "atividades em que se explore o erro com apoio da tecnologia informática". Neste caso, ao invés de ser evitado, ele é observado pelo professor e refletido pelo próprio aluno. Nesse sentido, se utilizou alguns softwares em que exercícios eram propostos como jogos digitais e ao errar se fazia o aluno refletir, inclusive em equipe e com o professor.

\section{Desenvolvendo Objetos de Aprendizagem para Apoiar no Ensino de Matemática}

Durante as pesquisas de objetos de aprendizagem para apoiar no ensino de matemática, observou-se que para determinados conteúdos havia uma certa limitação de objetos de aprendizagem, o que fez com que parte da equipe do projeto se focasse no desenvolvimento de novos objetos de aprendizagem. Nesse processo, novos desafios surgiram, como a escolha da tecnologia a utilizar, e o projeto em si do OA, já que é importante que ele seja divertido para os alunos. Nesse sentido, optou-se principalmente por jogos para dispositivos móveis na plataforma Android onde os alunos pudessem exercitar conteúdos da matemática, já que nessa disciplina se demanda muita prática para um aprendizado eficiente e eficaz. A escolha por dispositivos móveis se deu após o levantamento diagnóstico sobre a familiaridade dos alunos com recursos de TIC em que se viu que grande parte já tinha contato com esses dispositivos e por observar a facilidade de manuseio das crianças e jovens com dispositivos de tela sensível ao toque.

No levantamento feito, viu-se que $88,84 \%$ dos estudantes afirmaram possuir algum dispositivo móvel. 17,68\% afirmaram possuir tablets, 14,95\% afirmaram possuir Smartphone, $22.11 \%$ afirmaram possuir notebook e $65,26 \%$ possuem celulares. $57,47 \%$ afirmaram utilizar seu dispositivo móvel para acesso à Internet. O levantamento feito trouxe como lição não só seus resultados, mas também serviu para mostrar a importância de, antes de implantar TICs na educação, sentir a realidade dos alunos da escola em que se vai trabalhar, e buscar também saber do seu interesse. Nesse sentido, os alunos foram questionados se gostariam de ter aulas de matemática utilizando o laboratório de matemática, e 75,16\% afirmaram que gostariam de ter esse tipo de aula.

Durante o desenvolvimento do projeto, houve o desenvolvimento de quatro objetos de aprendizagem: o Math Arrow, o Mega Quiz da Matemática, o Math Timer e o Equacionando. Os três primeiros tinham como foco fazerem os alunos responderem exercícios de matemática para diferentes conteúdos de forma dinâmica e atrativa e eram destinados a tablets. Para o desenvolvimento desses jogos, um dos desafios foi deixá-los atrativos visualmente e para isso o trabalho de designers gráficos foi muito importante. Os jogos foram inicialmente feitos sem essa preocupação e posteriormente receberam melhorias sugeridas por profissionais dessa outra área. 
O Math Arrow é um jogo que contém perguntas sobre um determinado conteúdo matemático e que para respondê-las, o jogador deve acertar uma das maçãs que caem aleatoriamente com a opção correta. Ao acertar, ele vai acumulando uma pontuação que é baseada no número de tentativas. Além disso, o jogador pode também utilizar uma opção de ajuda para tentar aprender mais sobre o conteúdo enquanto joga. O Mega Quiz da Matemática (MQM) é um aplicativo para Android no estilo quiz voltado exclusivamente para conteúdos matemáticos. O objetivo principal do MQM é tentar estimular o jogador a fixar corretamente os conceitos matemáticos por meio da diversão competitiva de se conseguir concluir o jogo respondendo corretamente as perguntas no aplicativo. O Math Timer é um jogo de perguntas e respostas em que o aluno poderá testar os seus conhecimentos na resolução dos problemas apresentados, e os alunos têm que acertar a resposta antes do tempo de resposta acabar (indicado por uma barrinha que vai diminuindo). O Equacionando é um OA que tem como foco as equações do $2^{\circ} \mathrm{Grau}$, com o propósito de induzir seus usuários a entender melhor a relação do $\Delta$ e dos coeficientes com as raízes da equação. A Figura 1 ilustra algumas telas dos jogos Math Arrow e Math Timer.

Figura 1. Telas dos jogos Math Arrow e Math Timer

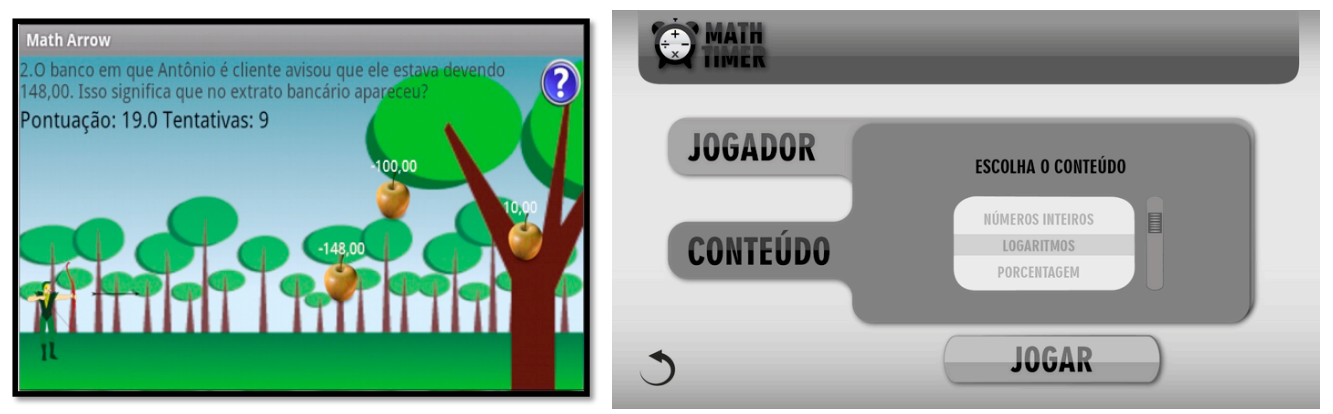

Durante o projeto se pôde desenvolver protótipos dos quatro OAs e foram efetivamente utilizados na escola o Math Arrow e o Math Timer. Ambos tiveram uma receptividade muito boa por parte dos alunos das escolas. Para as aulas com estes recursos, foram levados tablets e as turmas foram divididas em equipes.

\section{Considerações Finais e Trabalhos Futuros}

Este trabalho procurou apresentar alguns desafios do processo de inclusão digital no ensino de matemática e a experiência obtida com o Projeto InfoMat na superação desses desafios, como ideias para planejar aulas de matemática envolvendo TIC, para conhecer a realidade da escola, seus alunos e professores, para fazer a seleção de OAs a trabalhar, para desenvolver OAs, para efetivamente promover aulas usando TICs apesar de problemas de estrutura física das escolas, dentre outros aspectos observados. Acreditase que a experiência relatada aqui e os resultados deste projeto possam servir de inspiração para a realização de iniciativas semelhantes em outras escolas e para uma maior adoção do uso de recursos digitais no ensino de matemática pelos professores.

Como trabalhos futuros, espera-se dar continuidade às ações do projeto com mais professores e escolas e evoluir os objetos de aprendizagem produzidos, bem como avaliar outros objetos de aprendizagem existentes para apoiar o ensino-aprendizagem de matemática. 


\section{Referências}

Brasil (2006) Orientações curriculares para o ensino médio; linguagens, códigos e suas tecnologias. Brasília: Ministério da Educação, Secretaria de Educação Básica

Campos, G. H. B. Construção e validação de ficha de avaliação de produtos educacionais para microcomputadores. Rio de Janeiro, 1989. Dissertação (Mestrado) - Faculdade de Educação, UFRJ.

Castro Filho, J. (2007) Objetos de Aprendizagem e sua utilização no ensino de matemática. In: IX ENCONTRO NACIONAL DE EDUCAÇÃO MATEMÁTICA, Belo Horizonte. Belo Horizonte. Sociedade Brasileira de Educação Matemática.

Cury, H. (2007) Análise de erros: o que podemos aprender com as respostas dos alunos. Belo Horizonte: Autêntica.

Fernandes, A.; Castro Filho, J. ; Freire, R. ; Lima, L. (2009) Objetos de Aprendizagem na Escola: Estudo de um Modelo de Implementação. Disponível em http://www.proativa.vdl.ufc.br/publicacoes/artigos/7fbe24687c62b47d301c534ee2a2 153f.pdf. Acesso em: mai. 2015.

Healy, L., Jahn, A.P; Freant, J.B. (2010) Digital Technologies and the challenge of constructing an inclusive schools mathematics. In: BORBA, M. \& D'AMBROSIO, U. ZDM The International Journal on Mathematics Education. Springer.Vol.42(3-4) p. $393-404$.

Instituto Nacional de Estudos e Pesquisas Educacionais Anísio Teixeira (2013) Censo da educação básica: 2012. Resumo técnico. Brasília: Instituto Nacional de Estudos e Pesquisas Educacionais Anísio Teixeira.

Miskulin, R. (2009) As potencialidades didático-pedagógicas de um laboratório em educação matemática mediada pelas TICs. In: Lorenzato, S.(Org.). O Laboratório de Ensino de Matemática na Formação de Professores. Campinas, São Paulo: Autores Associados.

Peres, A., Lorenzi, F., Franco, T. (2014) "Castelo da Matemágica: um adventure textual aplicado ao ensino". XXV Simpósio Brasileiro de Informática na Educação. UFGD Dourados, MS.

Reategui, E.; Finco, M. D. (2010) "Proposta de Diretrizes para Avaliação de Objetos de Aprendizagem Considerando Aspectos Pedagógicos e Técnicos”. RENOTE 8, no. 3.

Toda, A., Carmo, R., Neto, J., Silva, A., Brancher, J. (2014) Desenvolvimento de uma aplicação web para auxiliar no ensino da Matemática para alunos do Ensino Fundamental. XXV Simpósio Brasileiro de Informática na Educação. UFGD Dourados, MS.

Valente, J. (1997) O computador na sociedade do conhecimento. Campinas: Unicamp. NIED.

Van de Walle, J. (2009). Matemática no Ensino Fundamental: formaçago de professores e aplicaçago em sala de aula. Traduçago: Paulo Henrique Colonese. 6.ed. Porto Alegre: Artmed.

Zimmerman, B. (1998) A Social Cognitive View of Self-Regulated Academic Learning. Journal of Educational Psychology, Vol. 81 (3), p. 329-339 